\title{
THE IMPORTANCE OF THE CONCEPT AND MEANING OF PLACE IN TOURISM GEOGRAPHY
}

\author{
Ali Movahed ${ }^{1}$ \\ Associate professor in Kharazmi University of Tehran \\ Kamran Jafarpour Gahlehteimouri ${ }^{2}$ \\ Researcher in Kharazmi University of Tehran \\ (Email: space.kamran@gmail.com)
}

Received date: 01-04-2019

Revised date: 01-07-2019

Accepted date: 13-07-2019

Published date: 11-09-2019

To cite this document: Mohaved, A. \& Gahlehteimouri, K. J. (2019). The Importance of the Concept and Meaning of Place in Tourism Geography. Journal of Tourism, Hospitality and Environment Management, 4(16), 01-09

DOI: $10.35631 / \mathrm{JTHEM} .416001$

\begin{abstract}
The place is one of the most complicated issues in geographical studies. Place refers to both sides of human and physical geography. There is not clearly understand about the place and sometimes refer to local, area, point, region, and landscape. Tourism geography is about different human and physical characteristics that conduct groups of people to move to a specific place "tourism destination". Therefore, tourist moves have tied to so many different geographical concepts, aspects, and meanings of place. Different places have different identity and geography searches for these uneven distributions of place. Rapid move from one place in the earth to another place is possible by advanced transportation systems. Hiding and destroying the function and meaning place behind space in geography will minimize the success of entire geographical studies in particular tourism geography. No matter how fast human be "speed" shortening "distance" and the "time" of trips faster than decades ago, but they have never been able to carry what are attached to place. The first question is, are we at the end of the real meaning of the place and does place losing the meaning. The second question is how the ability to move from one place to another place has changed the concept and meaning of the place. A library research method and process involve gathering appropriate information. This study aims to show how tourism geography in terms of formation, activity, and significance in shaping and reshaping the new meaning of the place. Also, the evolution of the meaning and function of place in the context of space.
\end{abstract}

Keywords: Place, Tourism Geography, Concept, Spatiality, Meaning

\section{Introduction}

Place is one of the most important and complicated concepts in geography. However, it has never been a clear where is place in human geography starts and where it ends. The human geography present place in very complicated relation between place is humanist, 
phenomenological, and radical (including Feminist, Marxist, and Postcolonial) (Williams, 2015 and Svensson, 2019). Place is not and it will never be a subject in human geography alone and it is a subject in entire geography. It does not matter how far or close is a place in physical geography and how "remote" and "inaccessible" (Tuan, 2013) as far as it "existent" (Disney, 2015) is somewhere in this world. According to the 1984 publication of the Joint Committee on Geographic Education's Guidelines for Geographic Education, there are five main themes in geography, which are consist of location, place, region, movement, and human-environment interaction. Geographers organize the space and they must understand the pattern and reason of moves and distributions of different human and physical geography. These five important themes are what formed our world, we live with them, and geography without them has no meaning (Carney, 2008). Therefore, tourism is a geographical subject before coming under any other realm of science. The tourist mind and tourism industry become more spatialized in compared to the decades ago. While the place still is the most important part of tourism geography without any doubt. However, the place as a tourism destination is not the same as what we knew/identified as the place. In fact, the place has changed the meaning and functional work/use that it uses to has and it has changed from an interconnected to an interdepended (Castree, 2003).

Place is developed and become more globalized and less interaction with surrounding/neighbouring areas. The place does not produce the meaning for a location and the meaning comes from outside (Castree, 2003).

The world is changing the meaning, definition, and concept of the place is changing but the place with never ends. Tourism is the modern human behaviour as far as a mathematical science, map, and navigation tools developed human shortened the distance between two points on the earth. The human had never had imagination from the other places when there was not a camera or easy Google Earth online navigation. The cyber world has changed the tourism imagination from the place and ability to reach go to another place. The trip was expensive, dangerous, and not available everywhere and for everyone. Columbus as the greatest explorer, navigator, and colonist made four voyages in 1492, 1493, 1498, and 1502. Vidal de La Blache (1926) in his book" principle of human geography" the geography is based on "observation" the other (Claval, 1981) in his book "La Nouvelle géographie" does not say that your place of observation is very important. Therefore, If we compare the journeys in Columbus by ship and with vertical observation then we know how a tourist imagination from the place can be different from Columbus. Checking on different types of destinations, comparing the price, booking a hotel and activities, navigating the place with your smartphone or on your laptop, gives you very good and different imagination about the place. In fact, part of you "mind" before you are in the destination. In past moving from one place to another place was based on simple maps and other experiences. Tourist has never had a single and simple idea about where he is going. The place was so abstracted his trip was very adventurous full of mysteries and unknowns. The place becomes more connected (tangible, visible, and observable) from thousands of kilometres. In the tourist mind, he is moving to a specific place. From the internet he knows what the best foods are, traditions, culture, best places to see, which restaurant serves what kind of dishes, which bar serve the best beer, checking on weather forecast and can find the season that he wants to be there, the best time for sky, beach, and seasonal view of that place. It does not matter if someone has ever been there or not, it is just enough to use Google map and make it possible for someone to observe and zoom in and find a place for his tourism destination. Linking a location to another location and linking a place to another place makes with new rapid transportation technologies make the distances shorter. Also, place identification on cyber world and in different navigation apps on smartphones or on the internet 
made the space sense of place stronger. A tourist is able to pay "transfer" upfront through the digital banking system. In short, place in general and in a particular place in tourism destination become much spatialized. What Hartshorne (1939) mentioned the place as "absolute" / "singular" concept in geography today does not work and does not exist. In contrast, today we know different place unique place, but we do not know the abstracted place is depended rather than connected. Place in geography is where a location physical and human aspects of that specific location meet each other (Castree, 2003). This theme of geography "place" is associated with the toponym (the name of a place), site (the description of the features of the place), and situation (the environmental conditions of the place) (Nag, 2017). Understanding of place without an understanding of space is impossible because a place is made and remade by/in space. Space has been always in geography and with geographers. Space has a broader meaning in geography, which can be consist of places, features, and even other spaces that a geographer put them together in combinations that are beginning to produce unexpected insights.

Once the geographers draw a line or a boundary, they are responsible to introduce a character for that specific area. This is what Hartshorne (1939) in his book The Nature of Geography mentioned that place the main concept in geographical studies and his areal differentiation place is very singular and abstracted. However, Castells believes that we live in a world that place has lost the meaning that it used to has and there are not the formal barriers. The place has changed by the space of flows, flows of goods, flows of information, flows of people, flows of finance, and the place is under the globalization influences that more than it has ever been. Castells (1996) believed we are in placeless planet and place is not isolated. Castree (2003) idea about the geographical sameness and the end of the place does not have geographical proof. First, the world is not changing as well as he mentioned in his paper. Second place has not the same meaning in the world and the meaning of place in the United States is different from Myanmar. Third, the flows do not have the same impact on the meaning and concept of place in the world. Forth, in some low level of human and environmental development countries (Poor African, Bangladesh, Pakistan, and countries at the end of Human Development Index) place is the most important concept/theme in geography. Fifth, if today the distances between two different and very far points on the earth are shorter in terms of the times and distance it does not mean that the place is dead.

Therefore, the place is not dead and still is the most meaningful theme in geography. Where we start and where we end is a place and in between, we pass through other places. What makes a person as tourist moves from one part the world to the other part of the world is "sense of place" and his imagination about "place". No matter what happened to the meaning and function of "place" since decades, years, and centuries before "the place still is there". However, place and space are intertwined but still; the place is the heart of space meaning comes from the landmark, building, mountain, river, cave, and any other man-made or natural phenomena. Sometimes the meaning and concept of the place draw/define from international interaction. What place as the resource has in that place make meaning of that place, but it has to be recognized by outside the place? Therefore, successful "tourism destination" should introduce a place in the world. A place consists of physical and human geographical aspects of a specific location. The main key ideas and theories in geography, refer to a place. We do not take a single step when we do not know where to go, Where to eat, where to live, where to enjoy, where is cold, where is hot, where is China Town, where to buy. Where refers to specific place character which in comparison to the other locations and places are different in terms of climatology, hydrology, pedology, topography, geology, geomorphology, and human characteristics. 
Tourism geography introduces attractive local, landscape, goods, and experiences to bring more tourism to a specific place. Each place has its own specifies and it is a strong tool to attract more tourists. The sense of place for local people is linked to their everyday life, but for tourists is like being closer to local people and culture. The things that people in local level participating in their daily activities are sense place. While they can introduce these activities to other people and they participate in the same activity, they will shape the same sense of place (Chammy and Li., 2019). When the tourist destination provides a cultural or religious source such as festivals or celebrations. On the other hand, the natural resources of tourism destination do not have the same use of the sense of place and tourist can be there and consume with or without the local people.

\section{Place Physical and Human Characteristics}

The place is an experimental point in space and tourism move from one place to another place to feel, touch, smell, see, and taste of that specific place. There are some important places in this world and tourist food destinations (e.g. Bangkok, Thailand. Bangkok's Chinatown is one of the best city districts for street food (Mateo-Babiano, 2012), Tokyo, Japan, Honolulu, Hawaii, Durban, South Africa, New Orleans, Louisiana, Istanbul, Turkey, Hong Kong, Paris, France.) The most beautiful tourist destinations for beautiful sceneries. Maroon Bells, USA, Grand Canyon, USA, Blue Ridge Mountains, USA, Beautiful Places: Oia, Santorini, Greece, Most beautiful places on Earth: Plitvice Lakes, Croatia, Interesting Places to Visit: Salar de Uyuni, Bolivia, Sossusvlei, Namibia, Torres del Paine National Park, Chile (Vacationidea, 2019).

Therefore, place is where tourist goes for a new experience or to find new things even business tourist, sports tourist, medical tourist, religious tourist, and sex tourist are included. The place is the heart of space where space gets meaning there is one or more than one place in space, which is like the spirit of the space. What we know as space (e.g. meaning, shape, and function, the degree of dependence or influence, and importance) is because of the role of place. What a place makes in the space and the place link to other places in other spaces makes the interaction between different spaces. The inner space interaction between different places will form the real a system of interactions. Some place form and shape in relation to the specific place and they have coexistence with other places. There are one or more than one hundred places inside a space. The place does not stand alone, and they have and is not an abstracted phenomenon in geography and place lives in relation, competition, and with other places. If the competition between two or hundreds or thousands of places is seriously, the place with limited resources will lose their position or they move to lower levels of completion. As a prime example, Iran before the revolution and in 1979 was one of the most interesting tourist destinations. After that, the Islamic government banned alcohol, destroyed the bars, and clubs in Tehran, Ramsar, Kish, Isfahan, and other places. After that, Istanbul in Turkey, Dubai in the Persian Gulf become the new tourist destination places. These are very important to know what kind of characteristics lets a place as tourism destination die or last longer. Also, what would be would be the results of place coexistence with other places? So, having perfect land full of tourism resources like Iran is not enough and Ideology can downgrade than the level and the meaning of the place and place lose the ability to coexist with other places. In past Iran designed cities to compete with Paris, New York, and London and now Islamic ideology put more on religious places Mashhad and Qom, and they invest on coexistence place Karbala and Najaf in Iraq.

A place will last longer not only because of what a place has because of what the coexistence places in lower or upper level have. Kuala Lumpur is one of the most tourist destinations in the 
world. On the other hand, in fact, Kuala Lumpur is located between Thailand in the north and Singapore in the south and sometimes tourist use Kuala Lumpur as a bridge to go to the other side. These countries are not very big and they climate and geographical features are the same. Some human characteristics made different places in these countries (e.g. Singapore is too urban, luxurious, and business centre; Malaysia cheap to live, big food industry; Thailand with the cheaper alcohol, food, and cost of living). Kuala Lumpur, Singapore, and Phuket in Thailand are coexisting places. In our memories we have we have a place and place is where we make our memories.

\section{Place and Space}

Space is consisting of interaction between one place with another place(s) and interaction between place(s) with other place(s). Space formation, shape and tendency relate to the interactions between places inside the space. Before 1990, space has never been a serious issue in social science studies in English, however, in geographical space has a long story. Germans have the biggest share with (918 items), French (454 items) and English (379 items). The postmodernist media theory in France increased the number of French books about space and exceeded English and German books (Gruning and Tuma, 2017). In geography's space is human geography production and place is physical geography's production.

In fact, space is made out of geographical boundaries and just consumed in geography and more by human geographers. The concept of space in geography has been very exotic and far from real geographical facts and is very one-sided. What in space has produced in geography was narrow, uncritical, and nongeographic. Differentiating between the meaning of space in Geography and other realms of science are difficult. What most of the geographers define as space is what accepted and agreed in other realms of science. If compare David Harvey's idea and definitions regarding space with sociology and psychology are too similar. In fact, they made in linguistics, philosophy, and sociology and then become a geographical subject. Since geography is divided into, human geography and physical geography concepts and definitions have produced in human geography.

Today differentiating between place (as is) and space (as is) is very difficult. People do not have the same feeling and sense of place from a place and it is something personal (Cresswell, 2009). People do not have a real understanding about space, they do not know how to measure it and they do not know well where it starts and where it ends. In most of the geographical departments, they really do not know what space is and sometimes they know space on the opposite side of the place. Tourists do not take a trip from one side to the other side to see a space of "what"!?. Tourist rather takes a trip from one side "place" to the other side "place" of the world to see "a place". The place is the first thing that human experienced more tangible, visible, measurable, and where people have memories. Space exists as long as place and it has been there, but nobody wanted to talk or mention it. In fact, they are as close as ever they have been, and they are going to be much closer. Today, place and space are so twisted, intertwined, interwoven, mixed, combined, and closed. As far as they are getting closer the place become more visible and space is diluting in the meaning of the place(s). Therefore, what makes the place different from the other place is not the exact place is the new meaning of the place and space in "person" mind.

\section{Globalization of Place}

Globalization diluted place in space and it made the new form of place-space, which is placed in the centre of that. How developed and advanced this world places is a very important concept 
in geography for existence as place the human stand on it and to be in somewhere. Existence in place needs to rely on specific material in particular places for interaction with other places. In the end, the most important aspect of the place is the particular meaning that place gives to meaning (Cresswell, 2011). While, most of scholar and thinker in geography and out of geography think that globalization means placeless world and the place will lose the meaning, function, and concept. On the other hand, if globalization is the sameness more similar facts and places in the world and place refers to uniqueness they are moving in opposite directions. In fact, place moves to be unique or as Hartshorne thought more singular and globalization try to push places to the same point or direction. The place is formed in different social, political, cultural, economic, human, and financial. With and without globalization place is not something made in out of place, and the place is the production of place what place has as resources. In addition, it does not matter how far the interaction of a place to another place in the context of the space. A place does not have a pure and merely one aspect (e.g. political, social, economic, and human and non-human). As far as the resource that exists in one place is important, the interaction between that specific places with another place become stronger. Therefore, the place is an engine of the power in space in comparison to other places and spaces. That is what will change the meaning, form, value, understanding, and influence of space and place. Place in the globalized world creates the group Identity (Monnet, 2011) or as mentioned by poststructuralist theorists (Murdoch 2006) conceptualized place and space as a dynamic, hybrid, and relational concepts (Cresswell, 2011). The place defines kind of human activities in the context of the space.

Persepolis as one of the most important places in the world and in Iran has been a very important tourist destination. People with different background want to see Persepolis. Cyberworld and social media have changed the semanticization of place in geography. It does not mean that place is what just are in a specific place. The concept and meaning of the place could have come from thousands of miles away. In tourism geography, it can go somewhere beyond the earth where the sun is. The attractive beaches where the sunlight's give a specific meaning to a place as a tourist destination like Bali Island in Indonesia. Pleasant environment is not necessarily important where some of the tourist destinations are located in unpleasant environment (e.g. Dead Sea and Cairo in Egypt).

\section{Place Categorization and Tourism Geography}

Place is the most important concept in geography and what makes "places" and different between places is much more important than place itself. The main geographical categorization of place is about the place categorization by culture, place categorization by climate, place categorization by human activities, place categorization by ethnics, place categorization by language, and place categorization by geographical location. Each place categorization attracts different people. This is where people provide a big network (Cresswell and Merriman, 2011) between different places in fact the categories that they are interested in. Figure 1 shows the different size of the place by categorization of aspect. A place by categorization takes in bigger scale as in the figure are shown by big blue circles. There are smaller sizes of place, which are places aspects and are shown by red circles. 


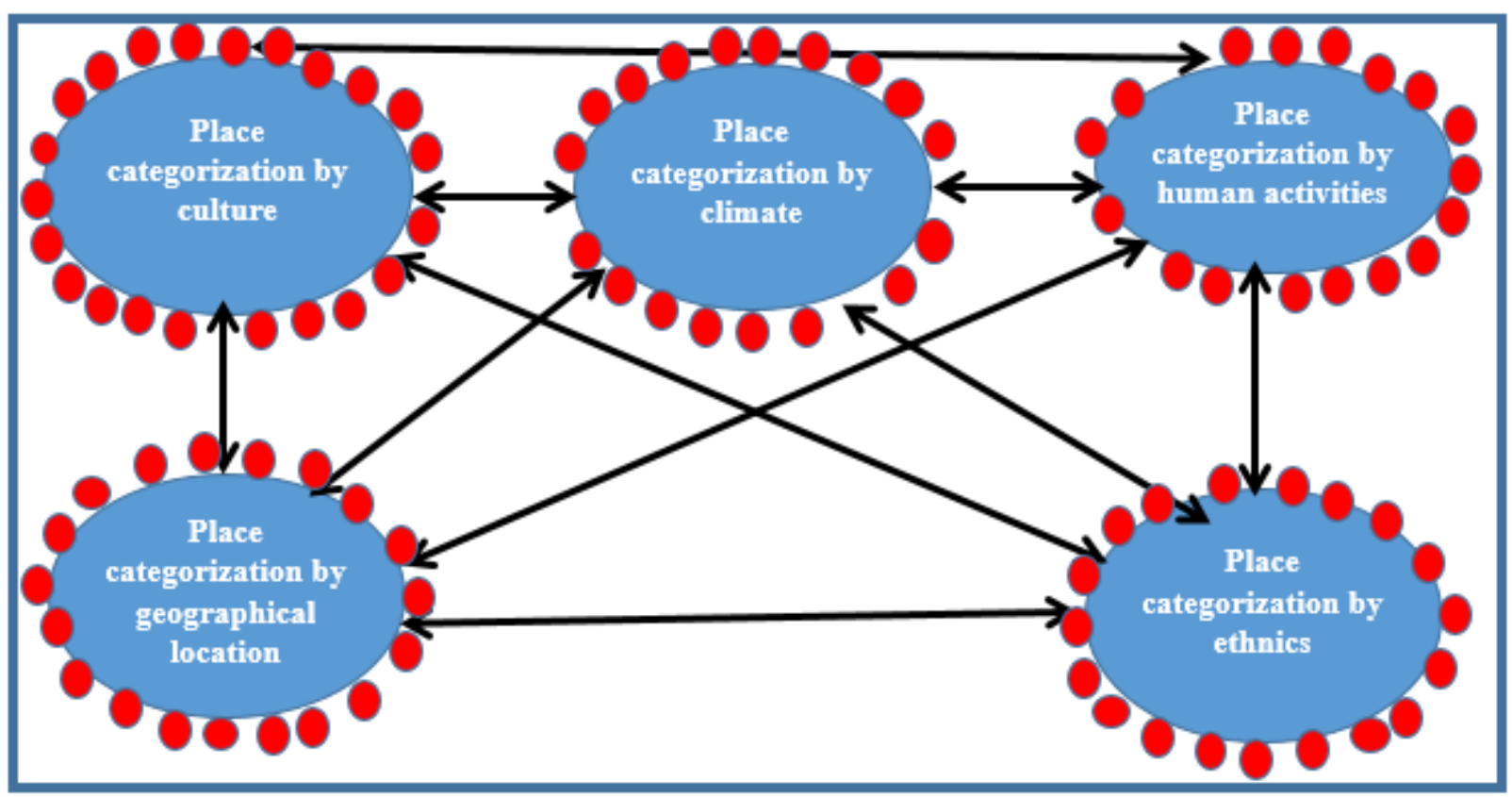

Figure 1: Place Categorization and Place Aspect

Where tourism geography starts but never finishes. The main idea of movements in tourists mind forms by "place categorization" and specified by "place aspect". Not all the everywhere in Egypt are important for tourist rather than the Pyramids. The Pyramids are the most important symbol "cultural aspect of place" in that inside the "cultural categorization of place". The massive tourist movements France has a bigger image of place from France as "cultural categorization of place" in Western countries "The Eiffel Tower" or "wine villages". So, this is divergence, movement, scale, mobilization, transportation technology is changing the form and size the place. This world will never be placeless or with the less influence of place.

The tourism geography is all about interaction between "natural resources" (e.g. animals, topographic features, trees, planets, and so on) and "users" human. Today, role of technology and knowledge is significant. Human observation on different places in the world and commercialized applications gives a clear idea about the place that they have never been. What people look for as tourist is "something special" the core of that somethings is a place. The natural structure and function change the quality, understanding, and sometimes quantity, and importance, duration in terms of spatial and temporal in place. On the other hands social structure and function of those who live in a specific place and those who come as tourist will change. In fact, where place gives its meaning is where the space gets meaning. By the better words, social, cultural, economic, and biodiversity of a place "create" those services that are interesting for tourists. The social and physical elements of a place make bridge between the place that tourist lives and the tourist destination.

\section{Conclusion}

It seems the place is more important than ever been in the different realm of science and in different disciplines. Yet, there is less attention to the place, and it has taken as absolute in terms of meaning and singular in term of functions. However, each step we take into geography is all about reaction to a place or from a place. Tourism geography is the best place it shows/identifies how the place in geography is important. When still people from a place take a trip to another place. Maybe years ago, geography had a meaning crisis as mentioned in this paper and place as the main concept in geography has been affected by this crisis (the 1940s 
and the 1950s). Accurate identification of space, scale, and time does not change the real meaning and function of place in geography.

Tourism in this paper was an example to show how place involves in different divisions and disciplines in geography. The place is important in urban planning, rural planning, and for environmental and climate change risk assessment. Place in geography is too complicated than what it is in other disciplines because the facts and the elements are very different. Understanding of place in geography requires deep knowledge in geographical science. The place does not merely belong to human geography or physical geography and the geographical place is combined with both.

Today the meaning and size of a place has changed, and it is as big as the space that gets meaning from a particular place. Moreover, this is the most complicated meaning of the space and place that we have ever had in geography, philosophy, mathematics physics, and social science. At last, place is not an abstracted topic, area, and a point. In addition, place is not something out of place which is forms by place or places. In fact, those who talked about space and place past they just talked about scale, function, form, accuracy (especially after GIS), but today the complexity of space and place is very important which provides better understanding of what space and place are or what "placespace" is.

\section{References}

Carney, G. O. (1999). Cowabunga! Surfer rock and the five themes of geography. Popular Music \& Society, 23(4), 3-29. doi.org/10.1080/03007769908591750.

Castells, M. (1996) The Rise of the Network Society. Oxford: Blackwell.

Castree, N. (2003). Place: connections and boundaries in an interdependent world. Key concepts in geography, 165-186.

Claval, P., 1981. La nouvelle géographie. FeniXX

Cresswell, T. Place: an introduction. John Wiley \& Sons, 2014.

Cresswell, T. (2011). Place: Part 1. In J. Agnew \& J. Duncan (Eds.), The Wiley-Blackwell companion to human geography (pp. 235-244).

Cresswell, T, and Merriman, P, eds. Geographies of mobilities: Practices, spaces, subjects. Ashgate Publishing, Ltd., 2011.

Disney, M. 2015. GEOGG141/ GEOG3051 Principles \& Practice of Remote Sensing EM Radiation (ii). UCL DEPARTMENT OF GEOGRAPHY

Grüning, B, and Tuma R. "Space, Interaction and Communication. Sociology in Dialogue with Spatial Studies: An Introduction." Sociologica 11, no. 2 (2017): 0-0.

Hartshorne, R. (1939) The Nature of Geography. Lancaster, PA: Association of American Geographers.

La Blache V, Paul, Martonne, E, and Bingham, M. T., "Principles of human geography." (1926).

Lau, Ch, and Li, Y., "Analyzing the effects of an urban food festival: A place theory approach." Annals of Tourism Research 74 (2019): 43-55.

Mateo-Babiano, I. B. (2012). Public life in Bangkok's urban spaces. Habitat International, $36(4), 452-461$.

Monnet, J. "The symbolism of place: A geography of relationships between space, power and identity." Cybergeo: European journal of geography (2011).

Svensson, D., 2019. The Patterns of Sense of Place: A Post-Structural Human Geography Case Study in HafenCity, Hamburg.

Tuan, Y.F., 2013. Landscapes of fear. U of Minnesota Press 
Vacationidea. 2019. 25 Most Beautiful Places in the World. https://vacationidea.com /getaways/most-beautiful-places-in-the-world.html

Williams, A., 2015. Place in Geography. International Encyclopedia of the Social \& Behavioral Sciences (Second Edition). 2015, Pages 149-152 